
\title{
25 Research Square \\ Overcoming Reproductive and Psychological Concerns of Breast Cancer Survivors: A Randomized Controlled Trial
}

\section{Samira Barjasteh}

Tehran University of Medical Sciences

\section{Farnaz Farnam}

Tehran University of Medical Sciences

Saharnaz Nedjat

Tehran University of Medical Sciences

Aymen M.A. Elsous

Israa University

Zohreh Khakbazan ( $\nabla$ khakbaza@sina.tums.ac.ir)

Tehran University of Medical Sciences

\section{Research Article}

Keywords: Sexual counseling, Breast cancer, Stress, Anxiety, Depression, Reproductive concerns, Sexual function

Posted Date: April 23rd, 2021

DOI: https://doi.org/10.21203/rs.3.rs-415634/v1

License: (1) This work is licensed under a Creative Commons Attribution 4.0 International License.

Read Full License

Version of Record: A version of this preprint was published at Journal of Family \& Reproductive Health on February 7th, 2022. See the published version at https://doi.org/10.18502/jfrh.v16i1.8594. 


\section{Abstract}

Background: After developing breast cancer, women experience changes in their sexuality, femininity, and fertility. These changes lead to poor mental health and increased psychological stress. Therefore, this study aimed to investigate the effects of Good Enough Sex (GES)-based, couple-centered group counseling on reproductive and sexual concerns of breast cancer survivors.

Methods: This was a quantitative randomized controlled clinical trial (RCT). After completing the informed consent forms, 100 women were assigned to the intervention and control groups (50 individuals per group) using randomized block design. The intervention included four 90-120-minute sexual counseling sessions with 2 and 3-month follow-ups. The data were collected using the sociodemographic and clinical characteristics, Persian version of Depression, Anxiety and Stress Scale (DASS21), Reproductive Concerns After Cancer (RCAC) scale, and Female Sexual Function Index adaptation for Breast Cancer patients (FSFI-BC). The obtained data were analyzed in SPSS 20 using descriptive and repeated measures analysis of variance (ANOVA) test.

Results: Significant differences were observed between the intervention and control groups in terms of the mean stress, anxiety, depression, reproductive concerns, and sexual function scores of the participants $(P<0.001)$. Therefore, the GES-based, couple-centered group counseling is associated with significant reductions in reproductive and sexual concerns of female breast cancer survivors.

Conclusions: The designed psychosocial training and counseling intervention effectively reduced reproductive and sexual concerns of female breast cancer survivors. Therefore, these training and counseling programs can be organized by relevant service centers to promote the reproductive health of women with breast cancer.

\section{Introduction}

Breast cancer is the most common cancer and the second leading cause of death from gynecological cancers worldwide $(1,2)$. In the United States, 1 in 8 women (about 12\%) will develop invasive breast cancer over her lifetime (3). According to the estimates of the Iranian Cancer Research Center, breast cancer was the most common type of cancer with the highest number of newly diagnosed cases in Iran in 2018 (4). The average age of breast cancer development in Iran has been reported to be at least 10 years lower than in developed countries (5). However, toady, the number of women recovering from cancer $(4,6)$ and the number of cancer survivors who will live for a long time (7) are growing. In countries like Iran, due to the young age of cancer survivors and women's reluctance to talk about sexual issues or to seek professional help, female survivors may have different concerns and needs than those in other countries $(8,9)$.

Following the initial treatment, women with breast cancer experience not only cancer-related taboos, but also changes in their sexuality, femininity, and fertility (10). Sexual dysfunction is the most common longterm consequence of cancer affecting the quality of sexual life of women with breast cancer. It can occur 
during the diagnosis or treatment period and can persist for years after the treatment. Due to its negative impact on the quality of life of survivors, sexual dysfunction can cause as much anxiety as the cancer itself (11). Breast cancer is a life threatening event that causes lots of stress and anxiety. The diagnosis of breast cancer is associated with common psychological problems such as stress and anxiety (12). Despite the development of different treatment methods, anxiety is often slightly controlled in cancer patients, and according to statistics, anxiety is highly prevalent (45-55\%) among breast cancer patients (13).

Studies have shown that women with cancer have different concerns about their reproductive health based on their age, type of cancer, time of diagnosis, and duration of treatment. These women can discuss their concerns with a reproductive health specialist before and during treatment (14). They should talk with a specialist about the effects of treatment on menstruation, pregnancy, and premature menopause. The specialist should assess the possibility of infertility and sexual problems, and examine alternative methods such as womb renting or follicle cryopreservation. In addition, since fertility is one of the most important functions of family, a couple who realize that they might never have children will experience some sort of infertility crisis, which can negatively affect all aspects of their lives, especially $\operatorname{sex}(15)$.

There are growing concerns about the impact of invasive breast cancer treatments (e.g. mastectomy) on patients' lives. Moreover, mastectomy is a highly prevalent surgical treatment for breast cancer in Iran (16), and its psychosocial consequences and postoperative rehabilitation care have been generally overlooked; therefore, several psychosocial and sexual interventions must be designed and evaluated to assess the reproductive health of these patients in Iran. Therefore, this is the first study to investigate the effects of Good Enough Sex (GES) counseling on sexual and reproductive concerns of female breast cancer survivors in Iran. The GES model aims to create an integrated approach to sexual health and treatment as a straightforward and constructive treatment map for couples(17).

It should be noted that this article is the product of a large research project (a

mixed method study). A qualitative article from the qualitative part of this study has been published (18). Inspired by the qualitative part of this study and the extraction of fertility and sexual concerns as the main concerns of women surviving breast cancer; The effectiveness of this intervention and the variables related to reproductive and sexual concerns of patients surviving breast cancer have been investigated.

\section{Materials And Methods}

\section{Study design}

We conducted a single center, randomized, parallel-group clinical trial in Urmia, Iran. Due to the nature of the intervention blinding was not possible.

\section{Setting}


The sampling site in the present study is Omid Hospital, West Azerbaijan, Urmia, Iran. An average of 1,500 cancer patients is admitted to the center each year. Meanwhile, cancer is the second leading cause of death in West Azerbaijan and Urmia is on the cancer-prone geographical line of the world, as it is very common among men with gastric cancer and among women with breast cancer (19). The age of breast cancer in Iranian women is 10 years lower than in other societies, while only $88 \%$ of women have never experienced mammography(20).

\section{Randomization Scheme}

Participants were divided into two groups (intervention and control) through blocked randomization. All possible modes were considered for the placement of letters A and B in four blocks producing six total possible modes. These six cases were numbered from 1 to 6 , whereas the number of the required 4-unit blocks was determined based on the number of the studied samples. The 100 participants were then divided into 25 blocks consisting of 4 participants each. According to the required number of blocks ( 25 blocks), random numbers were then arranged in a row based on a table of random numbers, and numbers greater than six were not considered. Based on the order of numbers extracted from the table, the blocks corresponding to each number were listed in order. Finally, when the samples entered the study, each participant took a specific letter in the resultant order. For instance, according to the order ( $A A B B / A B A B)$, the fifth participant was placed in Group A (intervention). Finally, the participants were divided into two groups of intervention and control based on the quadratic blocking method. The group assignments were concealed in a sealed, opaque envelope until clinic admission

\section{Sample size and sampling}

Participants were enrolled through convenience sampling. Sampling was performed on the population of married women with breast cancer admitted to Omid Hospital (Urmia, Iran) from April 2019 to July 2019. The sample sized was determined as 100 (50 individuals per group) based on the study of Khamseh et al. (21), using "difference between two independent means" formula in G*Power, and by rounding the obtained number and considering a loss to follow-up of $20 \%$. Participants were assigned to the intervention and control groups using randomized block design.

\section{Intervention}

The women in the intervention group (group A) received four 90-120-minute GES-based counseling sessions with weekly intervals. At the end of the study, the researcher sent the content of the training sessions in the form of 4 one-hour audio files to those in the control group via Telegram (the most popular messaging application in Iran). All the participants were also monitored for possible interventions performed at hospitals (e.g. visiting a counselor, attending training classes, etc.) during the study.

Finally, the status of the participants in both groups was assessed 2 and 3 months after the last session via telephone interviews with Persian version of DASS-21, RCAC, and FSFI-BC questionnaires. During the study, one individual in the intervention group and two people in the control group were excluded from the study due to either unwillingness to continue participation in the study or recurrence of the disease. 


\section{Inclusion and exclusion criteria}

All non-pregnant and non-lactating married women of reproductive age (18-49 years old) at the stage I, II, or Illa breast cancer with no other underlying or chronic disease whose husbands were at home for at least two weeks per month, and had experienced mastectomy procedure were enrolled. Another inclusion criterion was completing the radiotherapy and chemotherapy treatments at least six months and at most 5 years before the intervention. The main exclusion criteria included suffering from any physical or mental illness or any accident and mental trauma (confirmed by a physician) that can affect the sexual function of the woman/her husband, getting pregnant during the study, etc.

\section{Ethical considerations}

Consent was obtained from participants after explaining purpose of study. Anonymity and confidentiality were ensured and protected. In addition, voluntary participation was also ensured in which patients had right to withdraw anytime they felt a need to discontinue with the study. The study has been registered at Iranian Registry of Clinical Trials (IRCT20120609009975N8) and ethics code from the university (IR.TUMS.FNM.REC.1396.4865). Patients' information and the study data are kept in the corresponding author closet for at least one year.

\section{Measurements}

A semi-structured interviewed based questionnaire was used to collect necessary information. The first part was about socio-demographic (ten items) and clinical characteristics (six items) of participated women.

Second part was the Depression, Anxiety and Stress Scale (DASS-21): This 21-item scale was developed by Lovibond et al. in 1995 to measure the negative emotional states of depression, anxiety, and stress. It includes three 7-item self-report subscales of stress, depression, and anxiety. For each subscale, the items are scored on a 4-point Likert scale including not at all (score 0 ), slightly (score 1), highly (score 2), and extremely (score 3), and the overall score of each subscale is calculated separately (Min: 0; Max: 21) (22). Lovibond et al. (1995) confirmed the validity and reliability of the scale. To this end, they calculated the test-retest reliability of three subscales of depression, anxiety, and stress as $0.89,0.84$, and 0.82 , respectively. Internal consistency of the scale was also confirmed by calculating a Cronbach's alpha of 0.83 (22). Hosseini et al. (2006) assessed the psychometric properties of the Persian version of this questionnaire. The reliability coefficient of the tool was confirmed with a Cronbach's alpha of 0.96 indicating the acceptable reliability and validity of the whole scale (23).

Third part was the Reproductive Concerns After Cancer (RCAC) scale. This multidimensional scale was designed by Gorman et al. (2014) to assess a wide range of reproductive concerns of women of reproductive age surviving breast cancer. This scale contains 18 items that are scored on a 5-point Likert scale from strongly disagree (score 1) to strongly agree (score 5). This tool has six dimensions including concerns about "fertility potential", "partner disclosure", "child's health", "personal health", "acceptance, and "becoming pregnant" (24). Gorman et al. (2014) obtained an acceptable internal consistency and a 
reliability of 0.82 for this scale (24). The Persian version showed good validity as confirmed by 10 reproductive health specialists in which the item and scales content validity index were calculated accordingly. In addition, the internal consistency reliability was confirmed with a Cronbach's alpha of 0.87 .

Fourth part was the Female Sexual Function Index adaptation for Breast Cancer patients (FSFI-BC): This self-report scale was developed by Bartula1 and Sherman in 2015 (25). The subscales of this tool include changes after cancer ( 5 items), desire/arousal ( 6 items), lubrication (4 items), orgasm (3 items), pain (3 items), and distress (6 items). All items are scored on a 5-point Likert scale, only those related to the subscale of "lubrication" are scored on a 6-point Likert scale. Higher scores in each subscale indicate better sexual functioning. Scores lower than $18,9,9,24,12$, and 15 are interpreted as sexual dysfunction (requiring treatment) in the subscales of "changes after cancer", "desire/arousal", "lubrication", orgasm, pain, and distress, respectively. Masjoodi et al. assessed the validity and reliability of the Persian version of this scale. The scale had a high internal stability and acceptable test-retest reliability, as Cronbach's alpha of 0.81 and 0.74 were calculated for the sexually active and non-active groups, respectively. Internal correlation of 0.81 and 0.97 were also obtained for sexually active and non-active groups, respectively. Content validity index (CVI) and content validity ratio (CVR) were obtained as 0.80 and 0.60 , respectively (26).

\section{Analysis}

Descriptive statistics were used to summarize the quantitative findings of the study in the form of frequency distribution tables. Chi-square tests were used to assess the groups in terms of demographic variables and clinical characteristics of the participants. Repeated measures ANOVA test was used to assess the participants' sexual function and satisfaction during the study. All statistical calculations were performed in SPSS 20 based on the intention-to-treat principle $(P<0.05)$.

\section{Patient and public involvement}

Patients and/or the public were not involved in the design, or conduct, or reporting, or dissemination plans of this research

\section{Results}

Baseline and clinical characteristics of participated women:

Participated females' age are divided into three categories; $18-28,29-38$, and 39-49. Distributions of females are almost similar between intervention and control group. Majority of women in both groups are literate and have at least diploma. Common contraceptives used in the two groups are condoms, IUD and discontinuation (Table 1). Moreover, distribution of females based on age at time of diagnosis is also quite similar between intervention and control group. Most women underwent mastectomy in intervention (82\%) and control group (72\%). In addition, are also under hormonal therapy (76\% and $78 \%$, respectively) (Table 2). 
Table 1

Comparison of the demographic characteristics of the patients in the intervention and control groups

\begin{tabular}{|c|c|c|c|c|c|c|}
\hline \multirow[t]{2}{*}{ Variable } & & \multicolumn{2}{|c|}{$\begin{array}{l}\text { Control } \\
\text { group }\end{array}$} & \multicolumn{2}{|c|}{$\begin{array}{l}\text { Intervention } \\
\text { group }\end{array}$} & \multirow[t]{2}{*}{ Statistics } \\
\hline & & $\%$ & $\mathrm{~N}$ & $\%$ & $\mathrm{~N}$ & \\
\hline \multirow[t]{3}{*}{ Age of patient (year) } & $18-28$ & 18 & 9 & 12 & 6 & \multirow{3}{*}{$\begin{array}{l}X 2=1.89 \\
P=0.38\end{array}$} \\
\hline & $29-38$ & 36 & 13 & 38 & 19 & \\
\hline & $39-49$ & 56 & 28 & 50 & 25 & \\
\hline \multirow[t]{4}{*}{ Marriage duration (year) } & $0.5-2$ & 4 & 2 & 6 & 3 & \multirow[t]{4}{*}{$P=0.6$} \\
\hline & $2-5$ & 12 & 6 & 8 & 4 & \\
\hline & $5-10$ & 20 & 10 & 30 & 15 & \\
\hline & $>10$ & 64 & 32 & 56 & 28 & \\
\hline \multirow[t]{3}{*}{ Number of children } & 0 & 46 & 23 & 34 & 17 & \multirow{3}{*}{$\begin{array}{l}X 2=0.07 \\
P=0.12\end{array}$} \\
\hline & 1 & 30 & 15 & 50 & 25 & \\
\hline & $\geq 2$ & 24 & 12 & 16 & 8 & \\
\hline \multirow{4}{*}{$\begin{array}{l}\text { Level of patient's } \\
\text { education }\end{array}$} & Illiterate & 10 & 5 & 14 & 7 & \multirow{4}{*}{$\begin{array}{l}X 2=0.82 \\
P=0.41\end{array}$} \\
\hline & Under diploma & 54 & 27 & 40 & 20 & \\
\hline & Diploma & 20 & 10 & 32 & 16 & \\
\hline & Collegiate & 16 & 8 & 14 & 7 & \\
\hline \multirow{4}{*}{$\begin{array}{l}\text { Level of spouse's } \\
\text { education }\end{array}$} & Illiterate & 28 & 14 & 24 & 12 & \multirow[t]{4}{*}{$P=0.71$} \\
\hline & Under diploma & 28 & 14 & 22 & 11 & \\
\hline & Diploma & 40 & 20 & 46 & 23 & \\
\hline & Collegiate & 4 & 2 & 8 & 4 & \\
\hline \multirow[t]{3}{*}{ Economic status } & $\begin{array}{l}\text { Income more than } \\
\text { expenses }\end{array}$ & 16 & 8 & 24 & 12 & \multirow{3}{*}{$\begin{array}{l}X 2=0.66 \\
P=0.44\end{array}$} \\
\hline & $\begin{array}{l}\text { Income less than } \\
\text { expenses }\end{array}$ & 18 & 9 & 22 & 11 & \\
\hline & Income equals expenses & 66 & 33 & 54 & 27 & \\
\hline \multirow[t]{3}{*}{ Method of contraception } & Condom & 30 & 15 & 40 & 20 & \multirow[t]{3}{*}{$P=0.49$} \\
\hline & Contraceptives & 4 & 2 & 6 & 3 & \\
\hline & Discontinuous & 30 & 15 & 24 & 12 & \\
\hline
\end{tabular}




\begin{tabular}{|c|c|c|c|c|c|c|}
\hline & Progesterone ampoules & 4 & 2 & 2 & 1 & \\
\hline & IUD & 30 & 5 & 20 & 10 & \\
\hline & Without prevention & 2 & 1 & 8 & 4 & \\
\hline \multirow[t]{2}{*}{ Occupation of patient } & Employed & 26 & 13 & 34 & 17 & $X 2=0.76$ \\
\hline & Housewife & 74 & 37 & 66 & 33 & $P=0.38$ \\
\hline \multirow[t]{5}{*}{ Occupation of spouse } & Unemployed & 14 & 7 & 6 & 3 & $X 2=3.18$ \\
\hline & Labor & 18 & 9 & 12 & 6 & \multirow[t]{4}{*}{$P=0.52$} \\
\hline & Employed & 22 & 11 & 28 & 14 & \\
\hline & Self-employed & 34 & 17 & 36 & 8 & \\
\hline & Retired & 12 & 6 & 18 & 9 & \\
\hline
\end{tabular}


Table 2

Comparison of the clinical characteristics of the patients in the intervention and control groups

\begin{tabular}{|c|c|c|c|c|c|c|}
\hline \multirow[t]{2}{*}{ Variable } & & \multicolumn{2}{|c|}{$\begin{array}{l}\text { Control } \\
\text { group }\end{array}$} & \multicolumn{2}{|c|}{$\begin{array}{l}\text { Intervention } \\
\text { group }\end{array}$} & \multirow[t]{2}{*}{ Statistics } \\
\hline & & $\%$ & $\mathrm{~N}$ & $\%$ & $\mathrm{~N}$ & \\
\hline \multirow[t]{3}{*}{ Duration of disease (year) } & $1-5$ & 38 & 19 & 26 & 13 & \multirow{3}{*}{$\begin{array}{l}X^{2}=2.80 \\
P=0.24\end{array}$} \\
\hline & $5-7$ & 34 & 17 & 50 & 25 & \\
\hline & $7-10$ & 28 & 14 & 24 & 12 & \\
\hline \multirow{3}{*}{$\begin{array}{l}\text { Age at the time of } \\
\text { diagnosis (year) }\end{array}$} & $18-28$ & 26 & 13 & 22 & 11 & \multirow[t]{3}{*}{$P=0.78$} \\
\hline & $29-38$ & 34 & 17 & 36 & 18 & \\
\hline & $39-49$ & 40 & 20 & 42 & 21 & \\
\hline \multirow[t]{2}{*}{ Type of surgery } & Mastectomy & 82 & 41 & 72 & 36 & \multirow{2}{*}{$\begin{array}{l}X^{2}=1.41 \\
P=0.23\end{array}$} \\
\hline & Lumpectomy & 18 & 9 & 28 & 14 & \\
\hline \multirow[t]{3}{*}{ Stage of breast cancer } & 1 & 22 & 11 & 20 & 10 & \multirow{3}{*}{$\begin{array}{l}X^{2}=2.96 \\
P=0.22\end{array}$} \\
\hline & II & 40 & 20 & 56 & 28 & \\
\hline & III & 38 & 19 & 24 & 12 & \\
\hline \multirow[t]{4}{*}{ Drug treatment regimen } & Hormone therapy & 76 & 38 & 78 & 39 & \multirow{4}{*}{$\begin{array}{l}X^{2}=3.96 \\
P=0.41\end{array}$} \\
\hline & Herceptin & 4 & 2 & 4 & 2 & \\
\hline & $\begin{array}{l}\text { Herceptin plus hormone } \\
\text { therapy }\end{array}$ & 14 & 7 & 10 & 5 & \\
\hline & Without medicine & 6 & 3 & 8 & 4 & \\
\hline \multirow{4}{*}{$\begin{array}{l}\text { Breast cancer subtypes } \\
\text { (receptor variation) }\end{array}$} & HR+/HER2- & 70 & 35 & 64 & 32 & \multirow{4}{*}{$\begin{array}{l}X^{2}=1.92 \\
P=0.17\end{array}$} \\
\hline & HR-/HER2- & 16 & 8 & 20 & 10 & \\
\hline & HR+/HER2+ & 10 & 5 & 14 & 7 & \\
\hline & HR-/HER2+ & 4 & 2 & 2 & 1 & \\
\hline
\end{tabular}

Mean score comparison of DASS-21, RCAC, and FSFI-BC between intervention and control group:

According to Table 3, significant reduction in the mean score is observed between control and intervention group with regard to DASS-21 and RCAC $(P<0.001)$ two and three months after intervention. In return, significant increase is noticed in mean score of FSFI-BC $(P<0.001)$ two and three months post intervention. Within intervention group, significant differences are observed in the mean score of DASS- 
21, RCAC and FSFI-BC in at least two stages of study (before, two and three months post intervention) ( $P$ $<0.001$ ) (Table 3).

Table 3

Comparison Depression Anxiety Stress, Reproductive Concerns and Sexual Function before intervention, two and three months after the intervention in the intervention and control group

\begin{tabular}{|c|c|c|c|c|}
\hline \multirow[t]{2}{*}{ Variable } & Group & Control & Intervention & \multirow[t]{2}{*}{ Statistics } \\
\hline & Time & $\begin{array}{l}\text { Mean } \\
\pm S D\end{array}$ & Mean \pm SD & \\
\hline \multirow{5}{*}{$\begin{array}{l}\text { Depression Anxiety Stress Scales } \\
\text { (DASS-21) }\end{array}$} & $\begin{array}{l}\text { Before } \\
\text { intervention }\end{array}$ & $\begin{array}{l}49.22 \\
\pm 4.76\end{array}$ & $\begin{array}{l}48.61 \pm \\
5.06\end{array}$ & \multirow{3}{*}{$\begin{array}{l}F= \\
5248.61 \\
P<0.001\end{array}$} \\
\hline & $\begin{array}{l}\text { Two months post } \\
\text { intervention }\end{array}$ & $\begin{array}{l}48.96 \\
\pm 5.16\end{array}$ & $\begin{array}{l}32.14 \pm \\
4.99\end{array}$ & \\
\hline & $\begin{array}{l}\text { Three months } \\
\text { post intervention }\end{array}$ & $\begin{array}{l}48.46 \\
\pm 5.38\end{array}$ & $\begin{array}{l}32.10 \pm \\
4.98\end{array}$ & \\
\hline & \multirow[t]{2}{*}{ Tests } & $\begin{array}{l}\mathrm{F}= \\
1.48\end{array}$ & & \multirow{2}{*}{$\begin{array}{l}F= \\
12490.61 \\
P<0.001\end{array}$} \\
\hline & & $\begin{array}{l}P= \\
0.23\end{array}$ & $P<0.001$ & \\
\hline \multirow{5}{*}{$\begin{array}{l}\text { Reproductive Concerns After Cancer } \\
\text { scale } \\
\text { (RCAC) }\end{array}$} & $\begin{array}{l}\text { Before } \\
\text { intervention }\end{array}$ & $\begin{array}{l}74.08 \\
\pm 6.74\end{array}$ & $\begin{array}{l}74.34 \pm \\
1.01\end{array}$ & \multirow{3}{*}{$\begin{array}{l}F= \\
5662.56 \\
P<0.001\end{array}$} \\
\hline & $\begin{array}{l}\text { Two months post } \\
\text { intervention }\end{array}$ & $\begin{array}{l}73.64 \\
\pm 7.55\end{array}$ & $\begin{array}{l}46.31 \pm \\
0.76\end{array}$ & \\
\hline & $\begin{array}{l}\text { Three months } \\
\text { post intervention }\end{array}$ & $\begin{array}{l}73.28 \\
\pm 8.15\end{array}$ & $\begin{array}{l}47.51 \pm \\
1.02\end{array}$ & \\
\hline & \multirow[t]{2}{*}{ Tests } & $\begin{array}{l}F= \\
0.27\end{array}$ & & \multirow{2}{*}{$\begin{array}{l}F= \\
168880.71 \\
P<0.001\end{array}$} \\
\hline & & $\begin{array}{l}P= \\
0.76\end{array}$ & $P<0.001$ & \\
\hline \multirow{5}{*}{$\begin{array}{l}\text { Female Sexual Function Index } \\
\text { adaptation for Breast Cancer patients } \\
\text { (FSFI-BC) }\end{array}$} & $\begin{array}{l}\text { Before } \\
\text { intervention }\end{array}$ & $\begin{array}{l}80.64 \\
\pm 8.89\end{array}$ & $\begin{array}{l}80.62 \pm \\
9.40\end{array}$ & \multirow{3}{*}{$\begin{array}{l}F= \\
3814.96 \\
P<0.001\end{array}$} \\
\hline & $\begin{array}{l}\text { Two months post } \\
\text { intervention }\end{array}$ & $\begin{array}{l}80.58 \\
\pm 9.65\end{array}$ & $\begin{array}{l}95.66 \pm \\
6.43\end{array}$ & \\
\hline & $\begin{array}{l}\text { Three months } \\
\text { post intervention }\end{array}$ & $\begin{array}{l}80.38 \\
\pm 9.85\end{array}$ & $\begin{array}{l}95.83 \pm \\
6.29\end{array}$ & \\
\hline & \multirow[t]{2}{*}{ Tests } & $\begin{array}{l}F= \\
0.129\end{array}$ & \multirow{2}{*}{$\begin{array}{l}F=74.83 \\
P<0.001\end{array}$} & \multirow{2}{*}{$\begin{array}{l}F= \\
16541.95 \\
P<0.001\end{array}$} \\
\hline & & $\begin{array}{l}P= \\
0.87\end{array}$ & & \\
\hline
\end{tabular}


Considering the significance of the Repeated Measures ANOVA test, Bonferroni's Post Hoc test was used to provide a pairwise comparison of the means.

As shown in Table 4, in the intervention group, Bonferroni's test results showed that the mean score of DASS-21, FSFI-BC, and RCAC is significantly noticed between pre and two or three months post intervention $(P<0.001)$. However, no significant findings between post intervention periods, two and three months post intervention, $(P>0.05)$.

Table 4

Comparison Depression Anxiety Stress, Reproductive Concerns and Sexual Function before and after intervention in the intervention group

\begin{tabular}{|c|c|c|c|c|}
\hline \multirow[t]{2}{*}{ Variable } & \multirow{2}{*}{$\begin{array}{l}\text { Group } \\
\text { Time }\end{array}$} & & \multicolumn{2}{|l|}{ Intervention } \\
\hline & & & $\begin{array}{l}\text { Difference } \\
\text { of means }\end{array}$ & $\begin{array}{l}\mathrm{P}- \\
\text { value }\end{array}$ \\
\hline \multirow{3}{*}{$\begin{array}{l}\text { Depression Anxiety Stress Scales } \\
\text { (DASS-21) }\end{array}$} & \multirow[t]{2}{*}{$\begin{array}{l}\text { Before } \\
\text { intervention }\end{array}$} & $\begin{array}{l}2 \text { months after } \\
\text { intervention }\end{array}$ & 16.46 & $\begin{array}{l}< \\
0.001\end{array}$ \\
\hline & & $\begin{array}{l}3 \text { months after } \\
\text { intervention }\end{array}$ & 16.51 & $\begin{array}{l}< \\
0.001\end{array}$ \\
\hline & $\begin{array}{l}\text { Two months } \\
\text { post intervention }\end{array}$ & $\begin{array}{l}3 \text { months after } \\
\text { intervention }\end{array}$ & 0.04 & 0.72 \\
\hline \multirow{3}{*}{$\begin{array}{l}\text { Reproductive Concerns After Cancer } \\
\text { scale } \\
\text { (RCAC) }\end{array}$} & \multirow[t]{2}{*}{$\begin{array}{l}\text { Before } \\
\text { intervention }\end{array}$} & $\begin{array}{l}2 \text { months after } \\
\text { intervention }\end{array}$ & 28.02 & $\dot{c}_{0.001}$ \\
\hline & & $\begin{array}{l}3 \text { months after } \\
\text { intervention }\end{array}$ & 26.83 & $\stackrel{<}{<.001}$ \\
\hline & $\begin{array}{l}\text { Two months } \\
\text { post intervention }\end{array}$ & $\begin{array}{l}3 \text { months after } \\
\text { intervention }\end{array}$ & -1.19 & 0.91 \\
\hline \multirow{3}{*}{$\begin{array}{l}\text { Female Sexual Function Index } \\
\text { adaptation for Breast Cancer patients } \\
\text { (FSFI-BC) }\end{array}$} & \multirow[t]{2}{*}{$\begin{array}{l}\text { Before } \\
\text { intervention }\end{array}$} & $\begin{array}{l}2 \text { months after } \\
\text { intervention }\end{array}$ & -15.04 & $\iota_{0.001}$ \\
\hline & & $\begin{array}{l}3 \text { months after } \\
\text { intervention }\end{array}$ & -15.20 & $\stackrel{<}{0.001}$ \\
\hline & $\begin{array}{l}\text { Two months } \\
\text { post intervention }\end{array}$ & $\begin{array}{l}3 \text { months after } \\
\text { intervention }\end{array}$ & -0.16 & 0.69 \\
\hline
\end{tabular}

\section{Discussion}

The study presented a novel and significant findings. The study showed that implementing the psychosexual GES-based Counseling on Reproductive and Sexual Concerns of Female Breast Cancer Survivors has resulted in significant reduction in means score of stress, anxiety and depression using the DASS-21, reproductive concern was using the RCAC, and improvement of female sexual function using the FSFI-BC. Assessment of intervention was done twice; two and three months after intervention. 
The two groups were homogeneous in terms of disease features, personal characteristics, and socioeconomic status ( $P \otimes 0.05$ ), which can affect sexual outcomes of breast cancer survivors. Accordingly, duration of disease, type of surgery, and type of adjuvant therapy have been found to affect psychological outcomes and reproductive and sexual concerns of female breast cancer survivors (27, 28).

Cancer is a life threatening disease and breast cancer is the most common, deadly, and emotionally challenging disease in women (29). The results showed that the psychosocial approach of GES-based, couple-centered group counseling significantly reduces depression, anxiety and stress levels in female breast cancer survivors.

The result of a systematic meta-analysis (2018) showed that continuous supportive-cognitive therapy is the most effective psychological intervention in improving anxiety, depression, quality of life, and sexual function of female breast cancer survivors who have undergone mastectomy (30). The GES model emphasizes that physiological, psychological, and interpersonal relaxation is the basis of proper sexual functioning and high marital satisfaction. Physiological and psychological relaxation is lost when one tries too much to be perfect; this in turn causes functional stress and anxiety and results in a vicious cycle. Therefore, the development of cognitive, emotional, and behavioral skills is a prerequisite to sexual therapy (31). This is consistent with the results of the present study, as well as with the findings of Shandiz et al. (32). In the present study, we may attribute the participants' good psychological outcomes to improvements in their sexual indicators.

Khatibian et al. (2014) found that psychosocial interventions are helpful to cancer patients, because these interventions help patients cope with their negative automatic thoughts and replace them with positive thoughts; thus, they can reduce negative psychological outcomes in cancer survivors (33). This is consistent with the present results.

In line with the present findings, Nabipour et al. (2019) concluded that mindfulness-based cognitive therapy reduces depression, stress, and anxiety levels in female breast cancer survivors (34). Considering the effect of psychosocial approach of GES-based group therapy on psychological status of breast cancer survivors, as well as the interaction between mental health of these people and quality of their sexual lives, sex therapy programs must focus on psychological status of these individuals.

The GES-based counseling also significantly reduced productivity concerns of the participants. Breast cancer is a dreadful malignancy that affects the reproductive ability of women through cytotoxic effects of radiotherapy and chemotherapy treatments (35).

In a multifaceted prospective cohort study entitled "Cancer and Fertility", Vu et al. (2017) investigated the effect of training and counseling intervention on breast cancer survivors in the United States (36). The researchers provided women with face-to-face, telephone, and online training through group discussions and Q\&A sessions in cooperation with an oncologist and a fertility specialist. Vu et al. found that counseling and training programs provided along with routine cancer treatments encourage women with 
breast cancer to talk about their fertility concerns. These sessions also significantly increase the number of visits and telephone calls after face-to-face meetings, as well as the number of requests for assisted reproductive treatment, and reduce fertility concerns of these women (37). Accordingly, the present results confirmed the positive effect of counseling and training fertility sessions on breast cancer survivors. Kufel-Grabowska et al. (2020) investigated the effect of cancer and fertility counseling strategies on young women (under 45 years of age) with breast cancer. They concluded that the most appropriate time to provide fertility counseling is after diagnosis and before starting the treatment process. They also highlighted the need to reduce reproductive concerns of these women at any stage of life even after full recovery (38). This is consistent with the results of the present study, as well as with the findings of Macklon et al. (2019) (39).

In the review study of Deshpande et al. (2015), receiving fertility preservation counseling and obtaining information about the benefits and harms of assisted reproductive treatment was associated with improvements in the quality of life and psychological outcomes of female breast cancer survivors. They also argued that these women demand accurate, attainable, and standardized information to meet their reproductive and sexual health needs (40). These findings are in line with the results of aforementioned studies $(41,42)$.

The findings also showed that the GES-based group counseling significantly improves sexual function of female breast cancer survivors. The GES-based group counseling was designed creatively as a set of principles and rules in the form of a sexual cognitive-behavioral therapy to reflect the meaning and value of sex, accentuate sexual intimacy and psychological relaxation, and promote sexual function of the participants at the end of the intervention, as well as 2 , and 3 months after the intervention. This is in line with the results of Fatehi et al. (2019) (43).

Hamel et al. (2019) investigated the effect of sexual counseling (with cognitive-behavioral therapy approach) on participants' quality of sexual life, and observed that counseling can be adopted as a dynamic problem-solving process to improve the quality of sexual life (44). This is also consistent with the present results.

In another study conducted by Lampic et al. (2011) in Sweden, the researchers found that Fex-Can intervention (a web-based self-help training program) significantly improves sexual satisfaction and function of participants. Based on their findings, psychological interventions provide a wide range of psychosocial support to reduce feelings of sexual and reproductive inability, fear of the unknown and psychological distress. Lampic et al. predicted significant improvement in sexual function and satisfaction of young women with breast cancer (45). These findings are consistent with the present results, as well as with the findings of Farah et al. (2014) (46), León-Pizarro (47), Reese et al. (48), and Fatehi et al. (43) who investigated the effectiveness of "group training on sexual skills", "group counseling on sexual function and sexual quality of life in breast cancer survivors", "in-person training and telephone interviews on management of sexual concerns", and "psycho-sexual counseling on quality of life and sexual function", respectively. In line with the present results, some studies have highlighted 
the role of distance counseling and training (e.g. telephone interviews (49), Internet-based interventions (44)) on sexual function and sexual quality of life of female breast cancer survivors who have undergone mastectomy.

Despite its limitations, this is the first study conducted in Iran to determine effectiveness of psychosexual GES based counseling on reproductive and sexual concern. Due to cultural contexts, Iranians feel embarrassed to talk about sexual issues; therefore, the researcher provided a private environment and established an intimate relationship with the participants to encourage them to participate in the study.

\section{Conclusion}

The GES-based, couple-centered group counseling significantly reduced stress, anxiety, depression, and reproductive concerns of female breast cancer survivors, while improving their sexual function. In future, several psychosocial and multidisciplinary interventions can be performed with larger sample sizes to improve the sexual condition of breast cancer patients.

\section{Declarations}

Author's contributions: SB and FF conceived the study, SB implemented the GES-based counseling, SB and ZK led data collection, SN conducted the analysis. SN, SB and AE drafted the manuscript, FF, ZK and ZK provided substantive revisions. All authors approved the final manuscript

Funding: None

Conflict of interest: No conflict of interest was observed in this study.

Data sharing statement: The data of this study are available with the corresponding author upon request.

Patient and public involvement: Patients and/or the public were not involved in the design, or conduct, or reporting, or dissemination plans of this research

Ethics approval: Informed consent obtained from all participants after explaining purpose of study. Anonymity and confidentiality were ensured and protected. In addition, voluntary participation was also ensured in which patients had right to withdraw anytime they felt a need to discontinue with the study. All methods were carried out in accordance with relevant guidelines and regulations under Ethics approval and consent to participate. The study has been registered at Iranian Registry of Clinical Trials (IRCT20120609009975N8) on (18/04/2020) and the study was approved by the Tehran University of Medical Sciences' research ethics committee (IR.TUMS.FNM.REC.1396.4865) on (14/03/2018). Patients' information and the study data are kept in the corresponding author closet for at least one year.

Patient consent for publication: Not required. 
Acknowledgments: This manuscript was derived from a Ph.D. thesis in Reproductive Health. It was registered with the Ethics Code of IR.TUMS.FNM.REC.1396.4865 and Clinical Trial Code of IRCT20120609009975N8. The authors would like to thank the authorities of Research Committee of Tehran University of Medical Sciences as well as all the participating patients who never gave up hope.

\section{References}

1. Eloranta S, Smedby K, Dickman P, Andersson T. Cancer survival statistics for patients and healthcare professionals-a tutorial of real-world data analysis. Journal of Internal Medicine. 2021;289(1):1228.

2. Yazdani-Charati R, Hajian-Tilaki K, Sharbatdaran M. Comparison of pathologic characteristics of breast cancer in younger and older women. Caspian journal of internal medicine. 2019;10(1):42.

3. Zendehdel K. Cancer statistics in IR Iran in 2018. Basic \& Clinical Cancer Research. 2019;11(1):1-4.

4. Nafissi N, Khayamzadeh M, Zeinali Z, Pazooki D, Hosseini M, Akbari ME. Epidemiology and histopathology of breast cancer in Iran versus other Middle Eastern countries. Middle East Journal of Cancer. 2018;9(3):243-51.

5. Zarei M, Bagheri-Saweh MI, Rasolabadi M, Vakili R, Seidi J, Kalhor MM, et al. Breast cancer research in Iran: a scientometric analysis of publications output from 1991 to 2015 in Scopus. Electronic physician. 2017;9(2):3816.

6. Akbari ME, Sayad S, Sayad S, Khayamzadeh M, Shojaee L, Shormeji Z, et al. Breast cancer status in Iran: Statistical analysis of 3010 cases between 1998 and 2014. International journal of breast cancer. 2017;2017.

7. Dolatkhah R, Somi MH, Jafarabadi MA, Hosseinalifam M, Sepahi S, Belalzadeh M, et al. Breast Cancer Survival and Incidence: 10 Years Cancer Registry Data in the Northwest, Iran. International journal of breast cancer. 2020;2020.

8. Heinemann J, Atallah S, Rosenbaum T. The impact of culture and ethnicity on sexuality and sexual function. Current Sexual Health Reports. 2016;8(3):144-50.

9. Gharibi T, Gharibi T, Ravanipour M. Facilitators and barriers affecting sexual desire in elderly Iranian women: a qualitative study. Sexual and Relationship Therapy. 2019;34(2):228-41.

10. Abdollahzadeh F, Moradi N, Pakpour V, Rahmani A, Zamanzadeh V, Mohammadpoorasl A, et al. Unmet supportive care needs of Iranian breast cancer patients. Asian Pacific Journal of Cancer Prevention. 2014;15(9):3933-8.

11. Wang LY, Pierdomenico A, Brandt R, Lefkowitz A. Female sexual health training for oncology providers: new applications. Sexual medicine. 2015;3(3):189-97.

12. Huang H-M, Lai J-H, Huang T-W. Mediating effects of depression on anxiety and leisure constraints in patients with breast cancer. BMC women's health. 2019;19(1):1-8.

13. Ng CG, Mohamed S, Kaur K, Sulaiman AH, Zainal NZ, Taib NA, et al. Perceived distress and its association with depression and anxiety in breast cancer patients. PLoS One. 2017;12(3):e0172975. 
14. Ruggeri M, Pagan E, Bagnardi V, Bianco N, Gallerani E, Buser K, et al. Fertility concerns, preservation strategies and quality of life in young women with breast cancer: Baseline results from an ongoing prospective cohort study in selected European Centers. The breast. 2019;47:85-92.

15. Ljungman L, Ahlgren J, Petersson LM, Flynn KE, Weinfurt K, Gorman JR, et al. Sexual dysfunction and reproductive concerns in young women with breast cancer: type, prevalence, and predictors of problems. Psycho-Oncology. 2018;27(12):2770-7.

16. Najafı M, Neishaboury M, Ghafari N, Haghighat S, Memari F, Kaviani A. Surgeons' Perspectives on Surgery of Breast Cancer in Iran: The Pattern and Determinants. Archives of breast cancer. 2015:5863.

17. McCarthy B, Wald LM. Couples Therapy and Counseling. Management of Sexual Dysfunction in Men and Women: Springer; 2016. p. 365-70.

18. KHAKBAZAN Z, FARNAM F, NEDJAT S, DIZAJI SR, BARJASTEH S. "Breast Cancer Attack on Sexual Life" Sexual and Reproductive Health Concerns of Women Surviving Breast Cancer: A Qualitative Study. breast cancer.9:12.

19. Entezar Mahdi R, KHalkhali HR. Estimation burden of breast cancer in West Azarbaijan province in year 2013. Studies in Medical Sciences. 2017;28(8):1-7.

20. Tabrizi FM, Vahdati S, Khanahmadi S, Barjasteh S. Determinants of breast cancer screening by mammography in women referred to health centers of Urmia, Iran. Asian Pacific journal of cancer prevention: APJCP. 2018;19(4):997.

21. Khamse F, Zahrakar K, Mohsenzade F. The effect of practical application of intimate relationship skills (PAIRS) on enhancing sexual satisfaction and marital happiness in married wives. Positive Psychology Research. 2015;1(2):52-41.

22. Lovibond PF, Lovibond SH. The structure of negative emotional states: Comparison of the Depression Anxiety Stress Scales (DASS) with the Beck Depression and Anxiety Inventories. Behaviour research and therapy. 1995;33(3):335-43.

23. Hosini SM, Nazari MA, Rasooli M, Shakarami M, Hosini SM. The relationship of main family health and marital intimacy: Evaluating the mediating role of constructive and non-constructive conflict resolution styles. Thoughts and Behavior in Clinical Psychology. 2014;9(32):67-76.

24. Gorman JR, Su HI, Pierce JP, Roberts SC, Dominick SA, Malcarne VL. A multidimensional scale to measure the reproductive concerns of young adult female cancer survivors. Journal of Cancer Survivorship. 2014;8(2):218-28.

25. Bartula I, Sherman KA. The Female Sexual Functioning Index (FSFI): evaluation of acceptability, reliability, and validity in women with breast cancer. Supportive Care in Cancer. 2015;23(9):2633-41.

26. Masjoudi M, Keshavarz Z, Nasiri M, Kashani FL. Exploration unmet sexual needs and promoting sexual function in breast cancer patients, Tehran:A mixed study [A dissertation presented in partial fulfillmnet of th requiarements for the degree of Doctor of Philosophy (PhD)]: School of Midwifery And Nursing; 2019. 
27. Sharma N, Purkayastha A. Factors affecting quality of life in breast cancer patients: a descriptive and cross-sectional study with review of literature. Journal of Mid-life Health. 2017;8(2):75.

28. Miaja M, Platas A, Martinez-Cannon BA. Psychological impact of alterations in sexuality, fertility, and body image in young breast cancer patients and their partners. Revista de investigacion clinica. 2017;69(4):204-9.

29. Al Eid NA, Alqahtani MM, Marwa K, Arnout BA, Alswailem HS, Al Toaimi AA. Religiosity, psychological resilience, and mental health among breast cancer patients in kingdom of Saudi arabia. Breast cancer: basic and clinical research. 2020;14:1178223420903054.

30. Ye M, Du K, Zhou J, Zhou Q, Shou M, Hu B, et al. A meta-analysis of the efficacy of cognitive behavior therapy on quality of life and psychological health of breast cancer survivors and patients. Psychooncology. 2018;27(7):1695-703.

31. McCarthy B, Cohn D, Koman CA. Sexual equity and the good enough sex model. Sexual and Relationship Therapy. 2020;35(3):291-303.

32. Shandiz FH, Karimi FZ, Rahimi N, Abdolahi M, Anbaran ZK, Ghasemi M, et al. Investigating sexual function and affecting factors in women with breast cancer in Iran. Asian Pacific Journal of Cancer Prevention. 2016;17(7):3583-6.

33. Khatibian M, Shakerian A. The effectiveness of cognitive behavioral group therapy on decreasing depression, anxiety and stress in breast cancer women admitted to Ahwaz Medical Sciences Hospitals. Scientific Journal of Kurdistan University of Medical Sciences. 2014;19(4).

34. Nabipoor Gisi S, Rafieepoor A, Haji Alizadeh K. Effectiveness of mindfulness-based cognitive therapy (MBCT) on psychological symptoms in patients with cancer. Journal of Research in Behavioural Sciences. 2019;16(3):333-43.

35. Anchan RM, Ginsburg ES. Fertility concerns and preservation in younger women with breast cancer. Critical reviews in oncology/hematology. 2010;74(3):175-92.

36. Vu JV, Llarena NC, Estevez SL, Moravek MB, Jeruss JS. Oncofertility program implementation increases access to fertility preservation options and assisted reproductive procedures for breast cancer patients. Journal of surgical oncology. 2017;115(2):116-21.

37. Massarotti C, Scaruffi P, Lambertini M, Sozzi F, Remorgida V, Anserini P. Beyond fertility preservation: role of the oncofertility unit in the reproductive and gynecological follow-up of young cancer patients. Human Reproduction. 2019;34(8):1462-9.

38. Kufel-Grabowska J, Litwiniuk M, Marszałek S, Górecki M, Malinowska M, Doś J, et al. 192P Strategies and results of oncofertility counselling in young breast cancer patients. Annals of Oncology. 2020;31:S85.

39. Macklon KT, Fauser BC. The female post-cancer fertility-counselling clinic: looking beyond the freezer. A much needed addition to oncofertility care. Reproductive biomedicine online. 2019;39(2):179-81.

40. Deshpande NA, Braun IM, Meyer FL. Impact of fertility preservation counseling and treatment on psychological outcomes among women with cancer: a systematic review. Cancer. 
2015;121(22):3938-47.

41. Mody SK, Gorman JR, Oakley LP, Layton T, Parker BA, Panelli D. Contraceptive utilization and counseling among breast cancer survivors. Journal of Cancer Survivorship. 2019;13(3):438-46.

42. Stark SS, Natarajan L, Chingos D, Ehren J, Gorman JR, Krychman M, et al. Design of a randomized controlled trial on the efficacy of a reproductive health survivorship care plan in young breast cancer survivors. Contemporary clinical trials. 2019;77:27-36.

43. Fatehi S, Maasoumi R, Atashsokhan G, Hamidzadeh A, Janbabaei G, Mirrezaie SM. The effects of psychosexual counseling on sexual quality of life and function in Iranian breast cancer survivors: a randomized controlled trial. Breast cancer research and treatment. 2019;175(1):171-9.

44. Hummel SB, van Lankveld JJ, Oldenburg HS, Hahn DE, Kieffer JM, Gerritsma MA, et al. Sexual functioning and relationship satisfaction of partners of breast cancer survivors who receive internetbased sex therapy. Journal of sex \& marital therapy. 2019;45(2):91-102.

45. Lampic C, Ljungman L, Obol CM, Eriksson L, Wettergren L. A web-based psycho-educational intervention (Fex-Can) targeting sexual dysfunction and fertility-related distress in young adults with cancer: study protocol of a randomized controlled trial. BMC cancer. 2019;19(1):1-11.

46. Farah LK, Shahram V, Zeinab H. Sexual skills training, body image and sexual function in breast cancer. Procedia-Social and Behavioral Sciences. 2014;159:288-92.

47. León-Pizarro C, Gich I, Barthe E, Rovirosa A, Farrús B, Casas F, et al. A randomized trial of the effect of training in relaxation and guided imagery techniques in improving psychological and quality-of-life indices for gynecologic and breast brachytherapy patients. Psycho-Oncology: Journal of the Psychological, Social and Behavioral Dimensions of Cancer. 2007;16(11):971-9.

48. Reese JB, Smith KC, Handorf E, Sorice K, Bober SL, Bantug ET, et al. A randomized pilot trial of a couple-based intervention addressing sexual concerns for breast cancer survivors. Journal of psychosocial oncology. 2019;37(2):242-63.

49. Salonen P, Tarkka M-T, Kellokumpu-Lehtinen P-L, Åstedt-Kurki P, Luukkaala T, Kaunonen M. Telephone intervention and quality of life in patients with breast cancer. Cancer nursing. 2009;32(3):177-90.

\section{Supplementary Files}

This is a list of supplementary files associated with this preprint. Click to download.

- additionalfiles.docx 